\title{
EFFECT OF OXIDATION ON HIGH TEMPERATURE FATIGUE CRACK INITIATION AND SHORT CRACK GROWTH IN INCONEL 718
}

\author{
T. Connolley, M. J. Starink and P. A. S. Reed
}

Materials Research Group, School of Engineering Sciences
University of Southampton
Highfield, Southampton, SO17 1BJ, United Kingdom.

Abstract

Fatigue tests at $600^{\circ} \mathrm{C}$ in air were performed on U-notch specimens of wrought IN718, using 1-1-1-1 and 1-20-1-1 trapezoidal cycles. SEM examination and acetate replication was used to study crack initiation and growth. In support of the fatigue tests, thermal exposure experiments were performed on unstressed specimens to study surface and sub-surface primary carbide oxidation. Compared to a 1 second dwell, a dwell time of 20 seconds at maximum load had a beneficial effect on fatigue lifetime. Polishing the U-notch to remove broaching marks also had a beneficial effect on fatigue life. Multi-site crack initiation along the root of the U-notch was observed in fatiguc specimens. Many of the cracks initiated at bulge-like features, associated with the oxidation of sub-surface primary carbides. Crack initiation was first observed as early as $12 \%$ of the total fatigue life, with further crack initiation occurring as tests progressed. Short cracks in the U-notches grew at a constant rate, except when interactions between parallel cracks resulted in crack arrest or coalescence. Significant crack coalescence occurred towards the end of the fatigue life, producing a dominant defect which propagated rapidly to failure. Surface eruptions and localised surface deformation were observed in fatigue and unstressed thermal exposure specimens, demonstrating a considerable volume expansion when primary $(\mathrm{Nb}, \mathrm{Ti}) \mathrm{C}$ carbides oxidised. It is proposed that the misfit strains due to primary carbide oxidation were superimposed on the plastic strain field in the U-notch due to external loading. This would create local strains high enough to cause rupture of the matrix, hence initiating a fatigue crack. $\underline{\text { Introduction }}$

Inconel 718 (IN718) is a precipitation-strengthened nickel-based superalloy with many applications, such as components for gas turbines, liquid-fuelled rockets, high temperature plant and cryogenic systems. IN718 has good oxidation and creep resistance at service temperatures up to $650^{\circ} \mathrm{C}$, combined with high strength and fatigue resistance. These properties mean IN718 is widely used for gas turbine discs, which experience long periods at high temperatures in an oxidising environment. Varying engine speeds generate cyclic loads, producing conditions in which low cycle fatigue (LCF) can occur. The high temperature fatigue properties of IN718 have been extensively studied [1], paying particular attention to the effect of mechanical variables $[2,3]$, microstructure $[4,5,6]$ temperature and environment $[4,7,8,9]$ on the propagation of long fatigue cracks. Less is known about fatigue crack initiation and subsequent propagation when cracks are microstructurally and/or mechanically short. Use of long crack propagation data can lead to non-conservative estimates of component lifetimes [10,11], so there is a continuing requirement for short crack initiation and growth data for use in life prediction models. There is also a need for further understanding of high temperature crack initiation and growth in notch stress fields, such as the fir tree root fixings in the rims of gas turbine discs.

It is generally accepted that high temperature crack initiation can be caused by oxidation of primary carbides at the surface of components, either by the creation of a micro-notch or the formation of oxide intrusions along grain boundaries. 
For superalloys in general, primary carbides are of the form "MC", where "M" is $\mathrm{Ti}, \mathrm{Nb}$, Ta, Hf, Th or Zr. For IN718, the main primary carbide formers are $\mathrm{Nb}$ and $\mathrm{Ti}$. Enhanced crack initiation and growth due to preferential primary carbide oxidation has been observed in cast superalloys such as MAR-M $509[12,13]$ and IN100 [14, 15]. In cast alloys, primary carbides often have a script-like morphology, which react to form oxide intrusions from which fatigue cracks can grow. In wrought IN718, primary carbides usually have a globular morphology and the mechanism of fatigue crack initiation by carbide oxidation is likely to be different. In a study of notch-rupture sensitivity of IN718 [16], volume expansion of oxidising primary carbides was identified as a mechanism of environmentally assisted crack propagation, due to the stress intensifying effect of expanding particles at or near crack tips. In the same study, surface eruptions of oxidised phases were seen on polished specimens exposed for 1 hour at $650^{\circ} \mathrm{C}[16]$.

Primary carbide oxidation has been proposed as a mechanism of environmentally-assisted creep crack growth, due to the release of niobium onto grain boundaries, forming an embrittling $\mathrm{Nb}_{2} \mathrm{O}_{5}$ niobium oxide phase [17]. Recently, eruption-like features caused by oxidation of primary carbide particles were frequently observed at fatigue crack initiation sites in U-notch specimens machined from an extruded IN718 bar [18]. Further work provided evidence that volume expansion of oxidised primary carbides caused fatigue cracks to initiate U-notch specimens of IN718 at $600^{\circ} \mathrm{C}[19]$.

Published information on high temperature crack growth in IN718 for blunt notch geometries is limited. Bache et al. [20] studied the growth of pre-initiated semi-elliptical cracks of initial surface length $2 \mathrm{c} \approx 1 \mathrm{~mm}$ growing in a U-notch with a stress concentration factor 2.23. Very rapid, accelerating crack propagation rates were observed at $600^{\circ} \mathrm{C}$ in air, producing critical crack lengths within 2000 cycles. Assuming production turbine discs do not contain millimetre-size defects prior to entering service, it is desirable to obtain information on the natural initiation of cracks and their growth rates in the submillimetre size range from 10-1000 $\mu \mathrm{m}$. This information, combined with data available for longer cracks, will enable more accurate prediction of turbine disc fatigue lives.

In this paper, results of observations of high temperature crack initiation and growth in a U-notch geometry are presented and discussed for IN718 specimens taken from a turbine disc forging. The results also provide further information about the role of primary carbide oxidation in fatigue crack initiation.

\section{Material}

Material used for this study was taken from an Inconel 718 turbine disc forging, the composition of which is given in Table I. The forging was solution treated at $955^{\circ} \mathrm{C}$ for 1 hour followed by an air cool. It was then aged at $720^{\circ} \mathrm{C}$ for 8 hours, cooled at $50^{\circ} \mathrm{C} / \mathrm{h}$ to $620^{\circ} \mathrm{C}$, then aged at $650^{\circ} \mathrm{C}$ for a further 8 hours, finishing with an air cool.

The disc material had a non-equiaxed grain structure, with larger elongated grains (diameter approximately 30-70 $\mu \mathrm{m}$ ) surrounded by extensive regions of small, more equiaxed grains (diameter approximately 5-20 $\mu \mathrm{m}$ ). Grain boundaries were extensively decorated with $\delta$ phase particles of various morphologies, ranging from globular to almost continuous films. An SEM micrograph of the typical microstructure is shown in Figure 1. Primary $(\mathrm{Nb}, \mathrm{Ti}) \mathrm{C}$ carbides exhibited a globular morphology and were distributed in clusters throughout the microstructure. Some primary $(\mathrm{Ti}, \mathrm{Nb}) \mathrm{N}$ nitrides were also present. The mean area fraction of primary carbides and nitrides determined by image analysis on polished microsections was $0.48 \%$. Mean Vickers hardness $(30 \mathrm{~kg})$ measured on specimens extracted from the disc was $444 \pm 11 \mathrm{H}_{\mathrm{v}}$.

Table I: Chemical Composition of IN718 Material Studied.

\begin{tabular}{cc}
\hline Element & $w t \%$ \\
\hline $\mathrm{B}$ & 0.003 \\
$\mathrm{C}$ & 0.031 \\
$\mathrm{Mg}$ & 0.002 \\
$\mathrm{Al}$ & 0.46 \\
$\mathrm{Si}$ & 0.08 \\
$\mathrm{P}$ & 0.01 \\
$\mathrm{~S}$ & 0.0004 \\
$\mathrm{Ti}$ & 1.02 \\
$\mathrm{Cr}$ & 18.0 \\
$\mathrm{Mn}$ & 0.06 \\
$\mathrm{Fe}$ & 18.6 \\
$\mathrm{Co}$ & 0.43 \\
$\mathrm{Ni}$ & 52.9 \\
$\mathrm{Cu}$ & 0.10 \\
$\mathrm{Mo}$ & 3.02 \\
$\mathrm{Nb}+\mathrm{Ta}$ & 5.22 \\
\hline
\end{tabular}

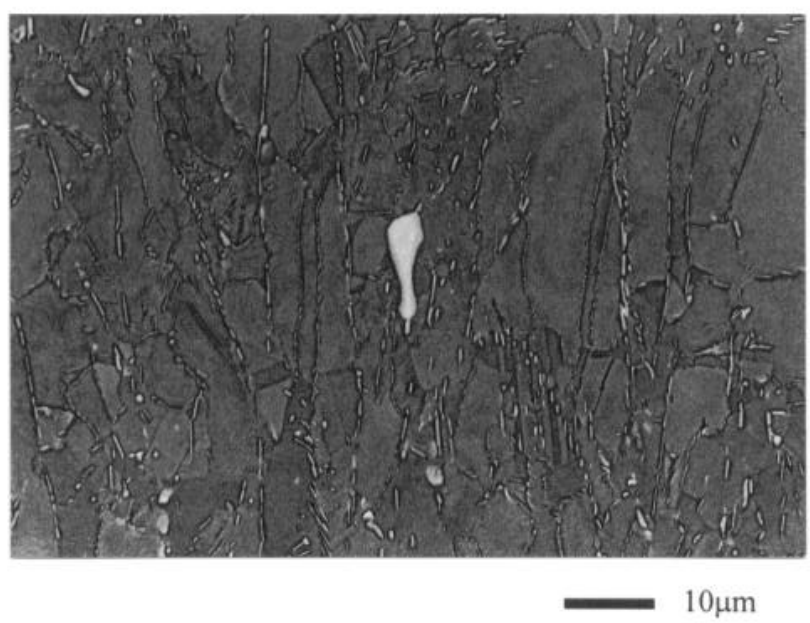

Figure 1: Backscattered electron image of typical microstructure. The bright feature at the centre of the image is an $(\mathrm{Nb}, \mathrm{Ti}) \mathrm{C}$ primary carbide.

\section{$\underline{\text { Experimental Procedures }}$}

Fatigue tests were performed on U-notch specimens extracted from the disc forging with their long axes tangential to the circumference and the notch axis parallel to the disc axis, as shown in Figure 2. The geometry of the U-notch specimen, shown in Figure 3, was designed to produce a stress concentration factor of 2.23. Notches were machined using a broaching process similar to that used to produce blade root fixings in the rims of production discs. The broaching process left long, straight marks running parallel to the notch axis. 


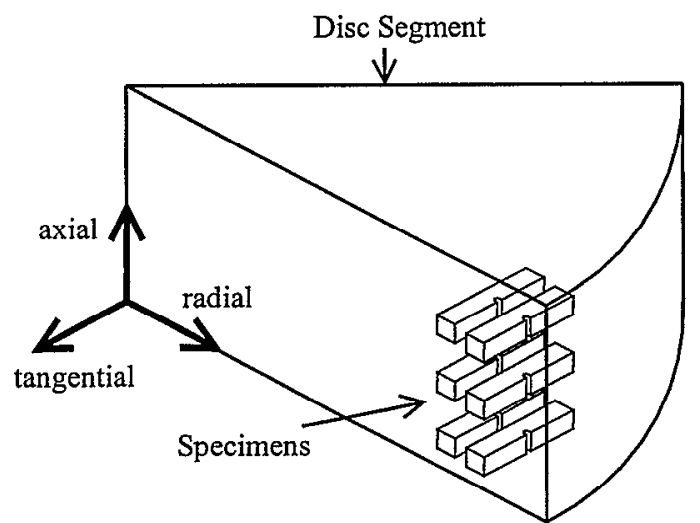

Figure 2: Orientation of U-notch specimens relative to disc forging.

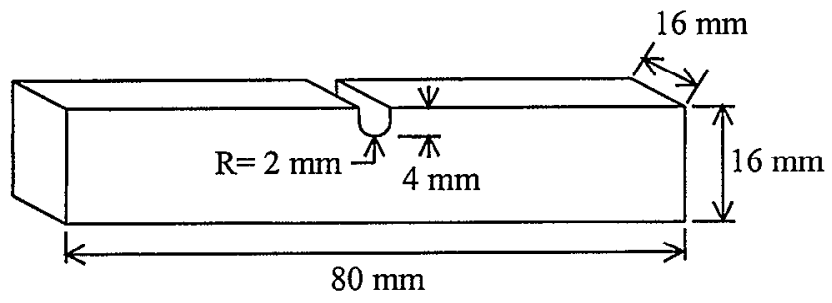

Figure 3 : U-notch specimen geometry.

Fatigue testing was conducted inside an ESH high temperature chamber mounted on an Instron 8501 servo-hydraulic testing frame. All tests were performed at $600+/-2^{\circ} \mathrm{C}$ in an air environment. Specimens were heated using four high intensity quartz lamps and the temperature was monitored and controlled via an R-type thermocouple attached to the front face of each specimen. Specimens were loaded in three point bend so that the maximum net section stress $\sigma_{\max }$ below the notch was $750 \mathrm{MPa}$, with an R-ratio of 0.1 . Tests were conducted under load control using 1-1-1-1 or 1-20-1-1 trapezoidal waveforms (see Figure 4).

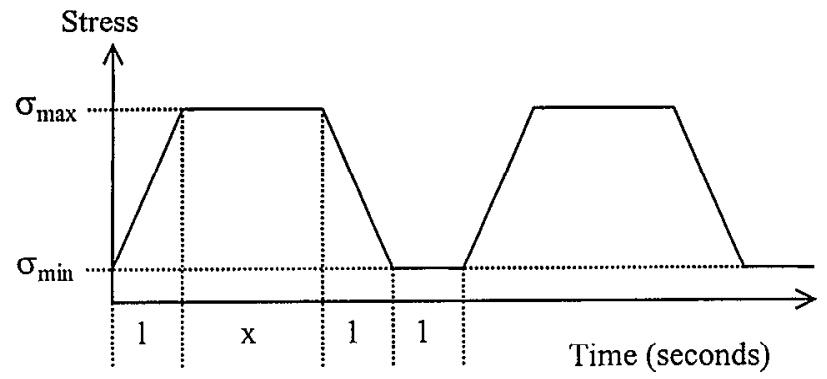

Figure 4: Trapezoidal waveform used for high temperature fatigue testing. $x=$ dwell time at maximum load: either 1 or 20 seconds.

Three fatigue tests are described in detail in this paper. Two of the tests were performed on specimens in the as-broached condition, using trapezoidal $1-1-1-1$ and 1-20-1-1 waveforms to study the effect of dwell time at maximum load on fatigue behaviour. The tests were interrupted periodically to enable scanning electron microscope (SEM) examination of the U-notch surfaces. A third
1-1-1-1 test was performed on a specimen with a polished U-notch, taking cellulose acetate replicas every 2000 cycles so that crack initiation and growth behaviour could be studied in more detail. Prior replication trials demonstrated that it was difficult to reliably distinguish between cracks and broaching marks in the U-notch. Therefore, the broaching marks were removed by polishing the notch to a $1 \mu \mathrm{m}$ diamond finish. To minimise enlargement of the notch, which can occur during manual polishing, the specimen was clamped in a specially-designed jig and polished using soft $4 \mathrm{~mm} \times 8 \mathrm{~mm}$ cylindrical dental felts mounted in a pillar drill.

SEM examination of the specimens during interrupted tests and after fracture was used to identify fatigue crack initiation sites and to investigate carbide oxidation. Energy-dispersive X-ray spectroscopy (EDX) was used to determine the chemical composition of features found at crack initiation sites.

In addition to the fatigue tests, thermal exposure experiments in air at $550^{\circ} \mathrm{C}$ were carried out on flat, unstressed samples of the IN718 disc material. Prior to exposure, the surface of each thermal exposure sample was polished to a $1 \mu \mathrm{m}$ diamond finish. Sample exposure times ranged from 1 to 256 hours. After exposure, specimens were examined using an SEM to look for signs of carbide oxidation on the surface. Cross-sections from selected specimens were nickel plated and prepared for metallographic observation to look for further evidence of surface and sub-surface carbide oxidation. The flat polished surface was used to provide a reference against which any deformation associated with sub-surface carbide oxidation could be checked.

\section{Results}

\section{U-notch Specimen Lifetimes}

Total fatigue lifetimes for the U-notch specimens are presented in Table II.

Table II : Specimen Lifetimes

\begin{tabular}{|c|c|c|}
\hline $\begin{array}{c}\text { Notch Surface } \\
\text { Condition }\end{array}$ & Waveform & $\begin{array}{c}\text { Lifetime } \\
\text { (cycles) }\end{array}$ \\
\hline As-broached & $1-1-1-1$ & 25311 \\
\hline As-broached & $1-20-1-1$ & 50756 \\
\hline Polished & $1-1-1-1$ & 51279 \\
\hline
\end{tabular}

The introduction of a 20 second dwell at maximum load resulted in almost double the fatigue life of the baseline test with 1 second dwell. (At the time of writing, a specimen with a 30 sccond dwell at maximum load had also exceeded double the life of the 1 second dwell test). This trend of increasing lifetime with increasing dwell is similar to that observed by the authors in their work on U-notch specimens extracted from extruded IN718 bar $[18,19]$. Polishing the notch to remove the broaching marks resulted in a significant increase in fatigue life for a 1-1-1-1 cycle at $600^{\circ} \mathrm{C}$. This is similar to previously published observations for as-broached and polished U-notch specimens tested using a $10 \mathrm{~Hz}$ sawtooth waveform in air at $600^{\circ} \mathrm{C}$ [18]. SEM observations of the interrupted as-broached tests and examination of replicas taken from the polished notch showed that crack initiation occurred 
within the first $12-20 \%$ of the overall fatigue life. After initiation, a significant proportion of the fatigue life was taken up by growth of numerous short cracks, with further crack initiation occurring as the tests progressed. Eventually, coalescence of cracks produced a dominant defect which propagated rapidly, assisted by further crack coalescence, until specimen failure occurred. Crack initiation and growth behaviour is described in more detail in the following sections.

\section{Short Crack Initiation}

Multi-site crack initiation along the root of the U-notch was seen in all fatigue tests. Three types of crack initiation site were observed: (i) sites with split, bulge-like features on the notch surface; (ii) sites where oxidised primary carbides had erupted out of the notch surface and (iii) sites with no distinct surface feature. An example of a crack initiation site in the notch root is shown in Figure 5.

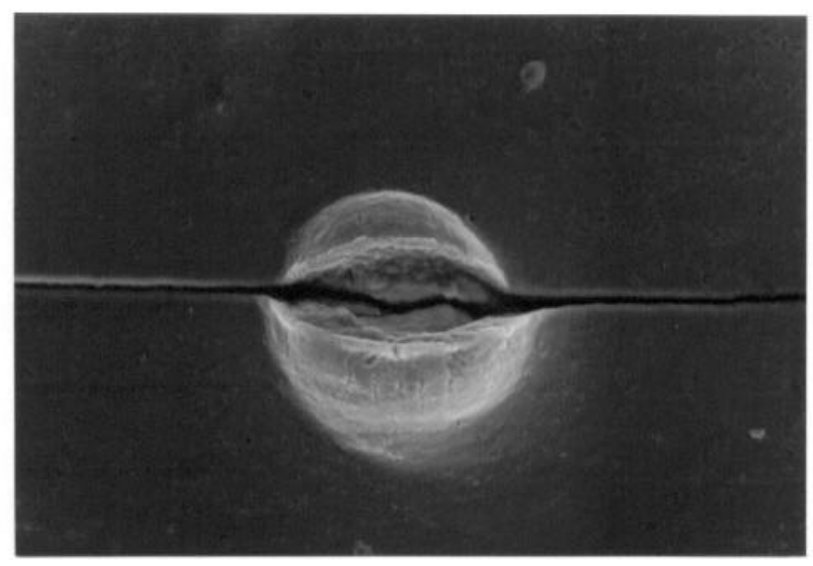

$10 \mu \mathrm{m}$

Figure 5 : SEM image in plan view of crack initiated at a bulgelike feature.

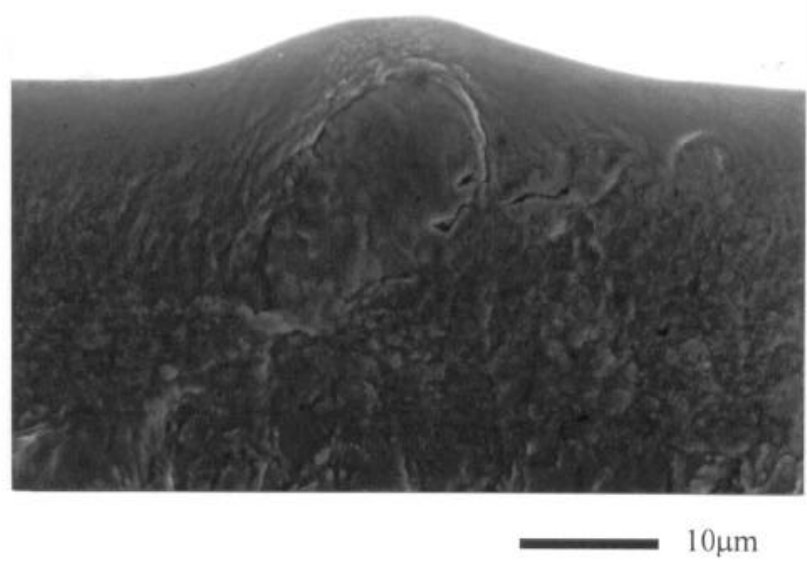

Figure 6: Post-fracture SEM image of main fracture surface, showing bulge and associated sub-surface particle at a crack initiation site.
During post-fracture examination, it was found that the bulge-like initiation sites had sub-surface particles associated with them, for example Figure 6. EDX analysis of the particles below the bulges confirmed they were oxidised primary carbides.

The replica record from the 1-1-1-1 polished notch test confirmed the early onset of crack initiation at bulge-like features. Cracks were first observed after 6000 cycles, which is within the first $12 \%$ of the overall fatigue life of 51279 cycles. Figure 7 shows the variation in the number of cracks observed as the test progressed. In the first half of the test, the number of surface cracks in the U-notch increased linearly with the number of cycles. Between 10000 and 30000 cycles the rate of nucleation of cracks from bulge-like features was calculated by linear regression to be $0.003 \mathrm{cracks} / \mathrm{cycle}$ with a correlation coefficient 0.98. After 30000 cycles the number of cracks observed approached a plateau. Beyond 44000 cycles, substantial crack coalescence led to an overall decrease in the number of cracks observed.

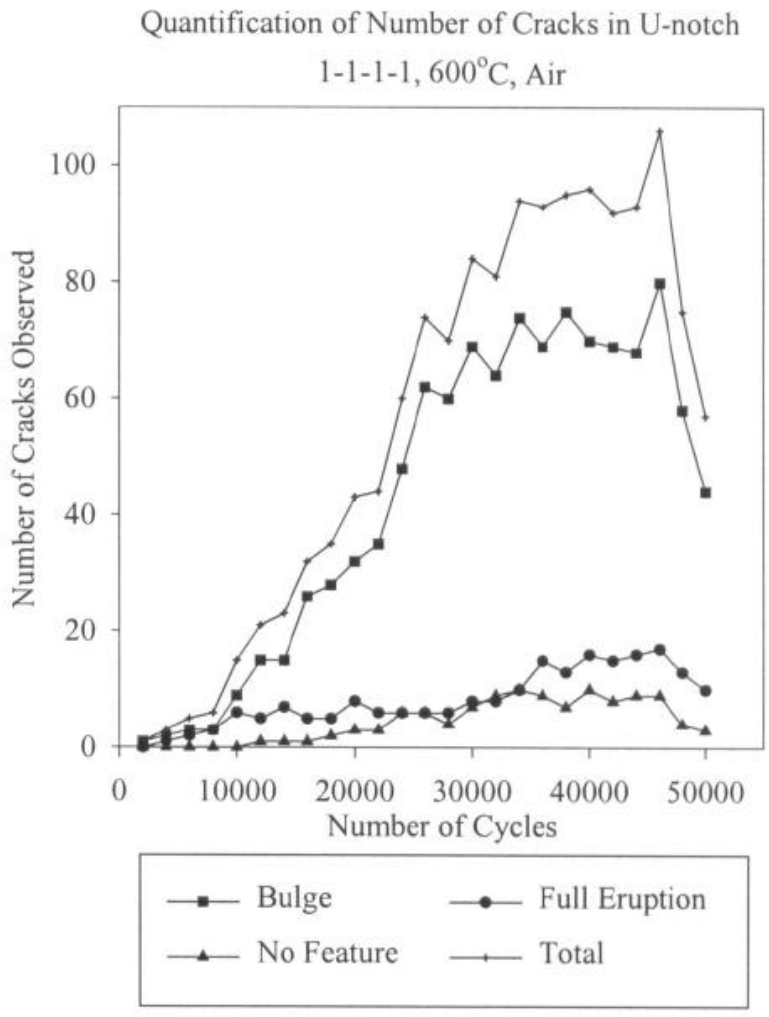

Figure 7 : Variation in number of surface cracks observed on replicas. 1-1-1-1, $600^{\circ} \mathrm{C}$, polished U-notch.

Not all of the cracks which initiated in notch roots coalesced to form the dominant final through-thickness defect. Results of postfracture SEM quantification of cracks which formed the throughthickness defect are listed in Table III. For the 1-1-1-1 test with a polished U-notch, 38 short cracks were identified which contributed to the final defect, whereas the replica record showed that over 100 cracks in total had initiated in the notch root. 
Table III : Quantification of cracks which coalesced to form the final through-thickness defect in U-notch specimens.

\begin{tabular}{|c|c|c|c|c|}
\hline \multirow[b]{2}{*}{$\begin{array}{l}\text { Waveform \& } \\
\text { Notch Surface } \\
\text { Condition }\end{array}$} & \multicolumn{3}{|c|}{ Initiation Site Type } & \multirow[b]{2}{*}{$\begin{array}{l}\text { Total } \\
\text { no. of } \\
\text { cracks }\end{array}$} \\
\hline & Bulge & $\begin{array}{l}\text { Full } \\
\text { eruption }\end{array}$ & $\begin{array}{c}\text { No } \\
\text { feature }\end{array}$ & \\
\hline $\begin{array}{c}1-1-1-1 \\
\text { As-broached }\end{array}$ & 12 & 0 & 14 & 26 \\
\hline $\begin{array}{c}1-20-1-1 \\
\text { As-broached }\end{array}$ & 16 & 3 & 9 & 28 \\
\hline $\begin{array}{l}1-1-1-1 \\
\text { Polished }\end{array}$ & 20 & 7 & 11 & 38 \\
\hline
\end{tabular}

The data in Table III provide further evidence of the importance of oxidised carbides as crack initiation sites, particularly the subsurface particles associated with bulges in the notch surfacc.

\section{Short Crack Growth}

The convention used for describing the length of cracks observed is shown in Figure 8. Surface cracks were defined as having a total length $2 c$, divided into two segments $c_{1}$ and $c_{2}$. Segment $c_{1}$ was the distance from the first crack tip to the middle of the initiation site and $c_{2}$ the distance from the second crack tip to the middle of the initiation site, so that $2 c=c_{1}+c_{2}$.

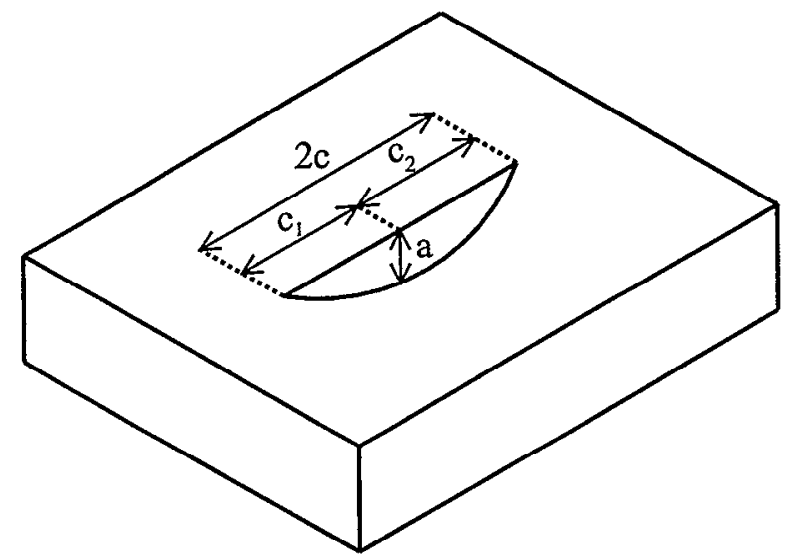

Figure 8: Convention used for describing crack lengths.

Crack length vs. cycle data for four typical surface cracks are presented in Figure 9. These four cracks were chosen because they initiated early in the fatigue life and exhibited behaviour typical of other cracks observed.

Crack I was first observed after 6000 cycles, in a large, shallow bulge-like feature. Its initial growth rate was slow, even arresting at one point, but then the growth rate accelerated until it reached an approximately constant value. Later in the test Crack I bccamc asymmetric about its initiation point, with segment $c_{1}$ growing more slowly than $c_{2}$. This retardation of segment $c_{2}$ probably occurred due to shielding by other cracks growing parallel to Crack 1 .
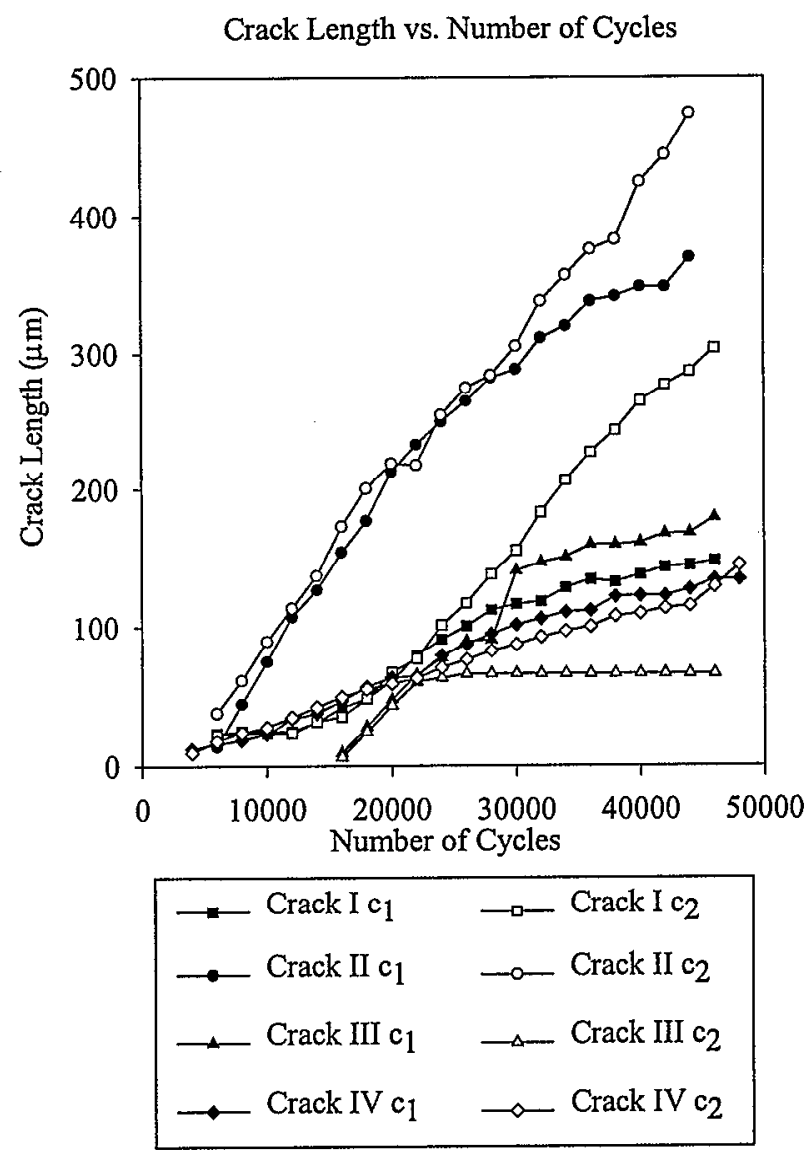

Figure 9: Crack length vs. number of fatigue cycles for four typical surface cracks. Waveform $1-1-1-1,600^{\circ} \mathrm{C}$, air environment.

Crack II initiated at a small surface eruption after 6000 cycles and was the fastest growing of all the cracks observed, averaging $\mathrm{d}(2 \mathrm{c}) / \mathrm{dN}=2.1 \times 10^{-8} \mathrm{~m} / \mathrm{cycle}$. Crack II reached a length of $2 \mathrm{c}=$ $840 \mu \mathrm{m}$ at 44000 cycles, after which coalescence with other cracks occurred and a dominant through-thickness crack formed. Like Crack I, Crack II became asymmetric about its origin later in the test, due to shielding of segment $c_{1}$ by other parallel cracks and possible interaction of their crack tip stress fields.

Crack III was first observed after 16000 cycles and initiated at a bulge-like feature. The development of this bulge can be seen in the sequence of images in Figure 10. Segment $c_{1}$ of crack III displayed a jump in length after 28000 cycles due to coalescence with a smaller crack directly in its path. The growth of crack III was suppressed at longer crack lengths, probably due to interaction with the crack tip stress fields of other cracks, with which crack III eventually coalesced. Segment $c_{2}$ of Crack III completely arrested until it coalesced with another crack after 48000 cycles.

Crack IV was first observed at a bulge-like feature after 4000 cycles and grew until coalescence with other cracks after 48000 cycles. 


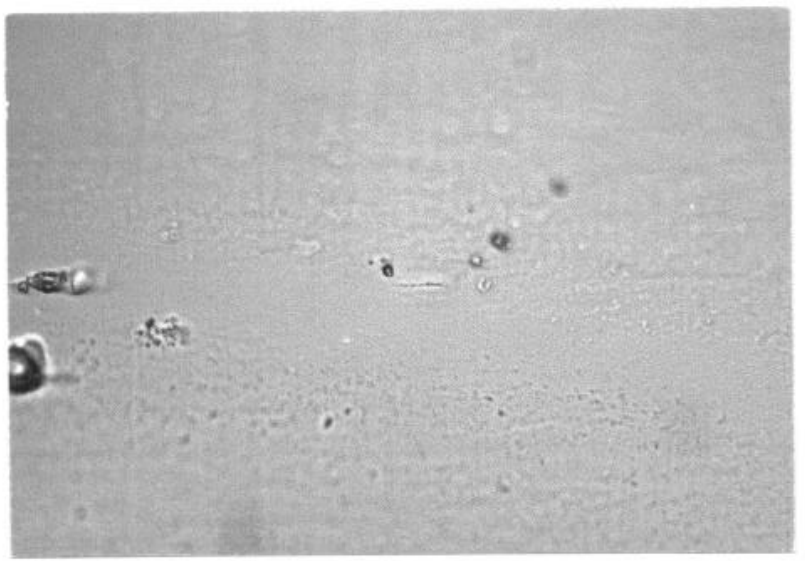

(a)

$50 \mu \mathrm{m}$

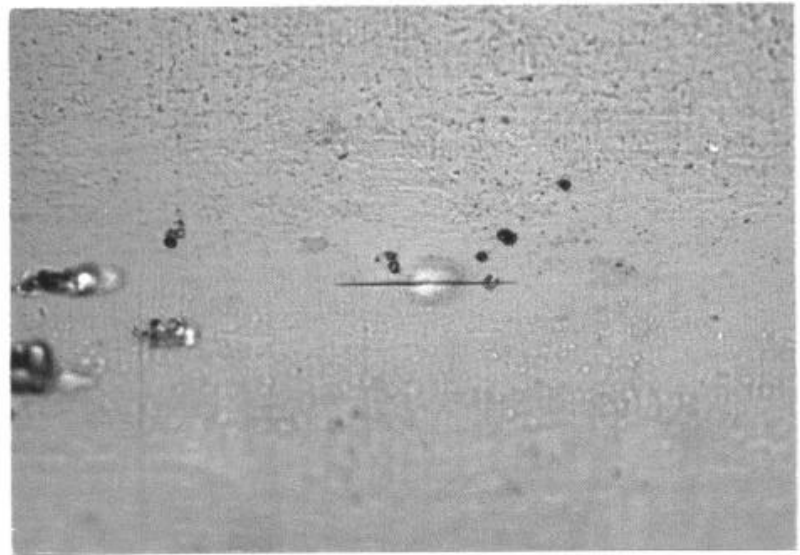

(b)

$50 \mu \mathrm{m}$

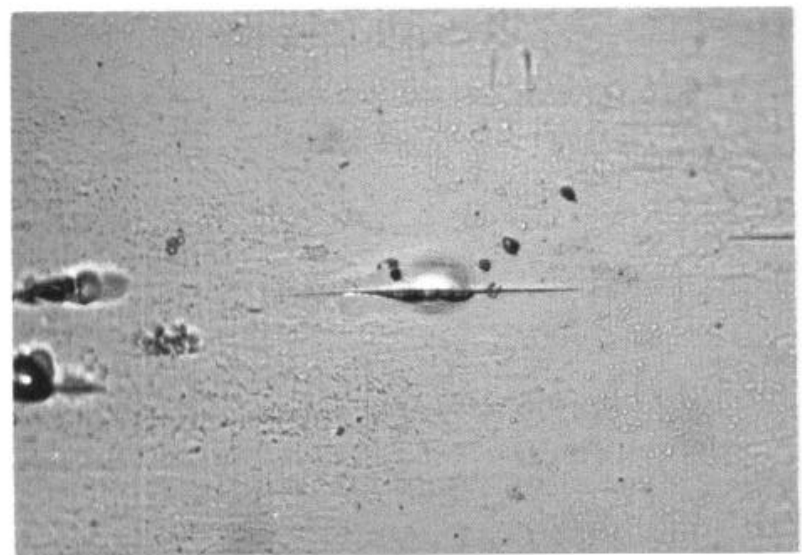

(c)

$50 \mu \mathrm{m}$

Figure 10 : Sequence of images from acetate replicas showing development of bulge at a crack initiation site. (a) 16000 cycles; (b) 18000 cycles; (c) 20000 cycles.
The growth rates of total surface crack lengths, $d(2 c) / d N$ are plotted in Figure 11 for cracks I to IV. The cracks appear to have approximately constant growth rates across a wide range of crack lengths (ignoring crack arrest events). This is in contrast to the usual trend of increasing growth rate with increasing crack length observed for long crack tests [1-9]. The surface cracks in the U-notches were all remarkably straight, with no deflections except those occurring during crack coalescence. It therefore appeared that surface crack propagation was transgranular, though SEM fractography indicated that propagation in the "a" direction into the bulk of the specimen became mostly intergranular beyond a distance of $30-50 \mu \mathrm{m}$ below the notch surface, shown in Figure 12.

Fatigue Crack Growth Rates in U-notch

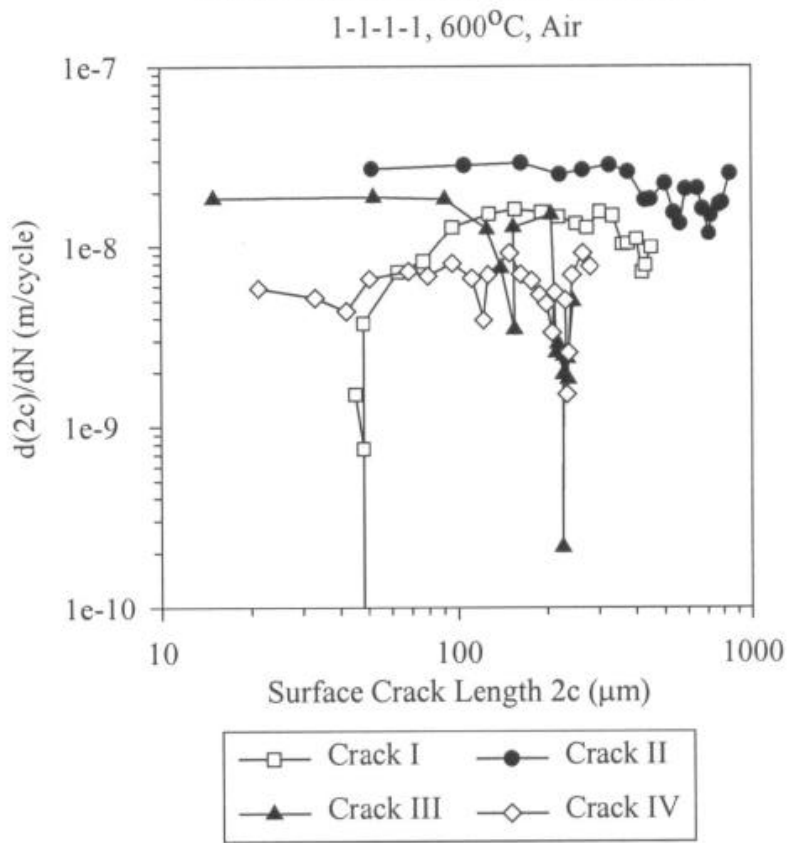

Figure 11: Growth rates of typical surface cracks in a U-notch. Waveform 1-1-1-1, $600^{\circ} \mathrm{C}$, air environment.

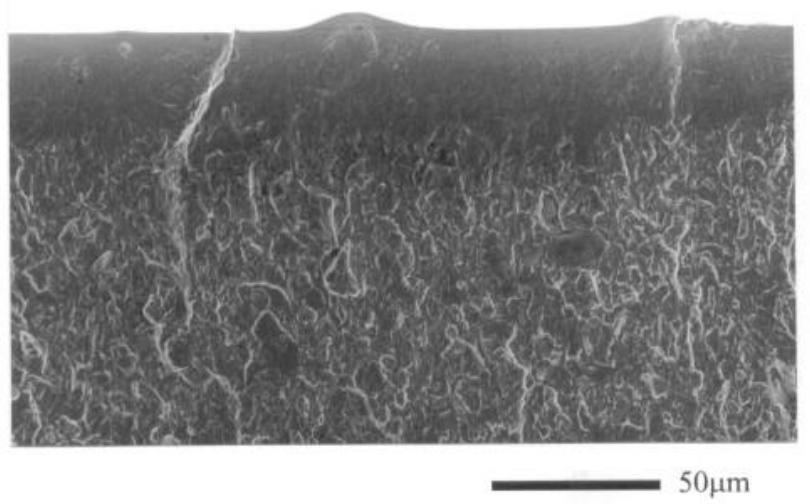

Figure 12: SEM image of fracture surface showing transition from very flat, transgranular fracture to intergranular fracture. Note the bulge at the crack initiation site. 


\section{Carbide Oxidation in Thermal Exposure Specimens}

Eruptions due to primary carbide oxidation were observed by SEM on the surfaces of all thermal exposure specimens, confirming the observations made by Sjoberg et al. [16]. When the specimens were tilted to view the eruptions from the side, many of the eruptions were seen to have a remarkable tower-like morphology (Figure 13). Other eruptions were more irregular in shape (Figure 14). Optical and SEM microscopy on cross-sections through the thermal exposure specimens showed that some subsurface oxidation of primary carbides had occurred, with associated bulges in the surface above (Figure 15). These bulges were similar to those observed at crack initiation sites in the U-notch fatigue specimens (Figure 6). Matrix deformation was also observed in the vicinity of some of the oxidised carbides which had erupted onto the surface. EDX confirmed that the surface eruptions and sub-surface oxidised particles were oxidised primary carbides.

Further optical microscopy and SEM performed on cross-sections through the thermal exposure specimens showed that in most cases, only carbide particles intersecting the surface had oxidised, even for the longest exposure time of 256 hours. Occasionally, sub-surface oxidised carbides like those shown in Figure 15 were observed, while other primary carbides at the same depth below the surface $(2-3 \mu \mathrm{m})$ were unoxidised. This suggests that a preferential diffusion path, such as a grain boundary, was required to produce sub-surface carbide oxidation.

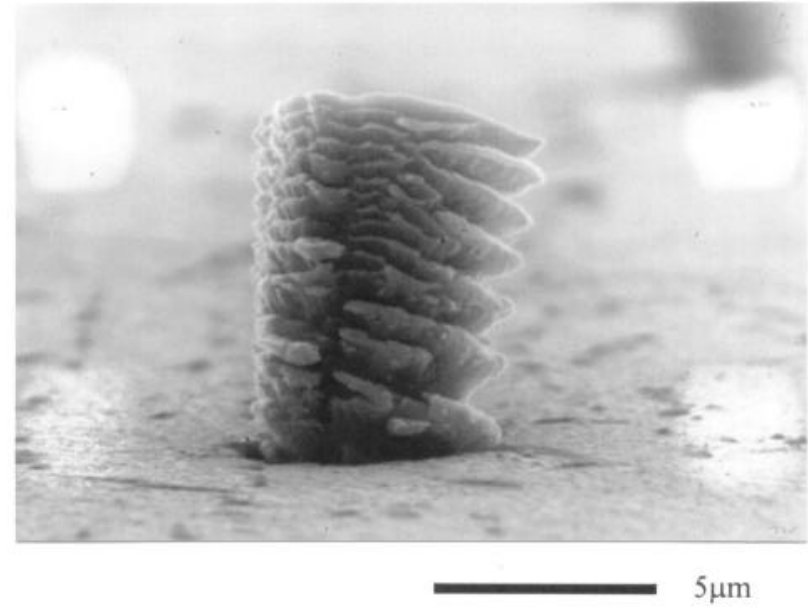

Figure 13: SEM image of tower-like morphology of oxidised primary carbide erupting from the polished surface of a thermal exposure specimen. 16 hours exposure at $550^{\circ} \mathrm{C}$.

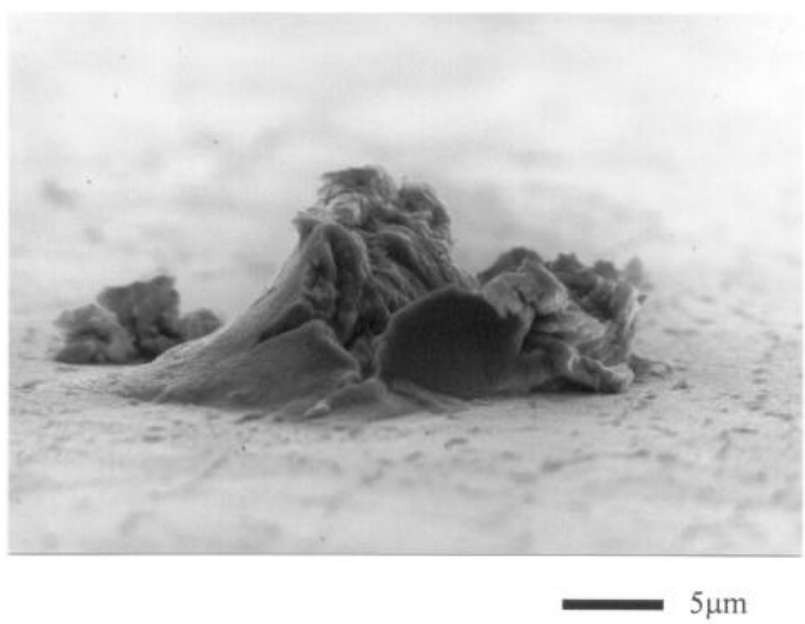

Figure 14: SEM image of irregular morphology of oxidised primary carbide erupting from the polished surface of a thermal exposure specimen. 16 hours exposure at $550^{\circ} \mathrm{C}$.

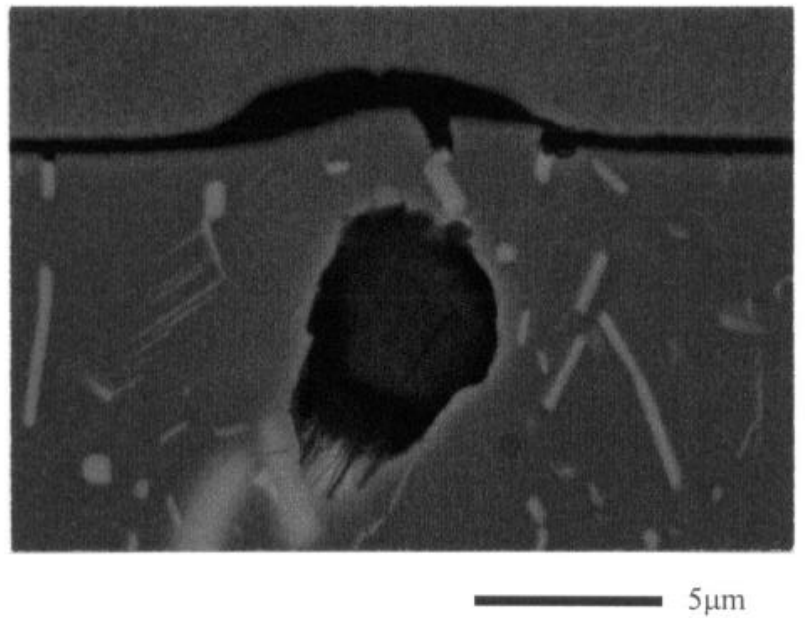

Figure 15: SEM backscatter image of sub-surface oxidised primary carbide in a thermal exposure specimen, showing associated local deformation of surface. 128 hours exposure at $550^{\circ} \mathrm{C}$.

\section{Discussion}

\section{Short Crack Initiation}

The results of the interrupted tests on U-notch specimens provide some insights into the role of primary carbides in fatigue crack initiation in IN718. Crack initiation commenced early in the fatigue life, with the majority of cracks observed on replicas initiating at bulge-like features. At first, crack initiation from bulge-like features occurred at a constant rate, before reaching a plateau which can be attributed to: (i) exhaustion of potential crack initiation sites; (ii) reduction in the local strain at initiation sites due to shielding by neighbouring cracks and (iii) crack coalescence. Post-fracture examination confirmed that a significant number of short cracks forming the main fracture initiated at bulge-like features with oxidised primary carbides below them. 
The surface bulges associated with oxidiscd sub-surface primary carbides in the fatigue specimens and thermal exposure specimens are evidence that plastic deformation of the surrounding matrix occurred during particle oxidation. In order to produce the observed bulges, the mismatch strains generated by carbide oxidation must be sufficiently high to cause matrix deformation. Pure $\mathrm{NbC}$ is known to oxidise rapidly between $490^{\circ} \mathrm{C}$ and $600^{\circ} \mathrm{C}$ to form $\mathrm{Nb}_{2} \mathrm{O}_{5}$ [21]. Estimating the volume expansion for the transformation of $\mathrm{NbC}$ to $\mathrm{Nb}_{2} \mathrm{O}_{5}$ in the temperature range 500 $600^{\circ} \mathrm{C}$ is problematic because $\mathrm{Nb}_{2} \mathrm{O}_{5}$ is polymorphic, and has been synthesised and observed in several different crystalline and amorphous forms [22]. It is not known what form is adopted by the oxide eruptions observed in $\mathbb{N} 718$, though a crystalline oxide form is considered to be more likely. Using available crystallographic data $[22,23]$, a maximum volume expansion factor of 2.28 was estimated for the transformation of $\mathrm{NbC}$ to $\mathrm{Nb}_{2} \mathrm{O}_{5}$. This estimate appears reasonable given the amount of volume expansion observed experimentally. Analytical solutions for the misfit stresses around a spherical particle in an infinite matrix $[24,25]$ were used to estimate the plastic zone size around an $\mathrm{NbC}$ particle which had transformed completely to $\mathrm{Nb}_{2} \mathrm{O}_{5}$. Using estimated mechanical property data for IN718, NbC and $\mathrm{Nb}_{2} \mathrm{O}_{5}$ at $600^{\circ} \mathrm{C}$, it was calculated that volume expansion by a factor of 2.28 would produce a maximum plastic zone radius of 4.2 times the particle radius. Although this simple estimate is for an infinite matrix and does not consider the situation of a particle close to the surface, the result demonstrates the potential for matrix deformation during primary carbide oxidation, as observed experimentally. Another phenomenon to consider is the evolution of $\mathrm{CO}$ or $\mathrm{CO}_{2}$ gas during carbide oxidation, but it is not known at this stage whether gas entrapment was a significant factor in bulge formation.

In the U-notch fatigue specimens, the misfit strains due to carbide oxidation were superimposed on the strain field due to loading. This may have created local strains high enough to cause rupture of the matrix in the vicinity of an oxidising particle, hence initiating a fatigue crack. The high incidence of bulges at crack initiation sites suggests that expansion of oxidising primary carbides was a significant mechanism of fatigue crack initiation in the notch root. The stress concentration effect of the notch root probably promoted stress-assisted oxygen diffusion, causing more rapid oxidation of the primary carbides than that observed for the unstressed thermal exposure specimens. Once a crack had initiated, the crack itself would provide another fast oxygen diffusion route to a sub-surface particle.

The total number of cracks initiated by oxidation of primary carbides and their initiation rate will be controlled by several factors. The number of primary carbides which are potential crack initiation sites will depend upon the number density of primary carbides in the material, their distribution relative to the notch surface and their distribution relative to preferential oxygen diffusion pathways such as grain boundaries. The rate of crack nucleation will depend upon the rate of primary carbide oxidation, which in turn is affected by the depth of individual carbides below the surface and the rate of oxygen diffusion to them. In addition, the plastic strain in the notch root due to external loading is not uniform, so that the local matrix strain around an oxidising particle will vary according to its position relative to the notch axis.

\section{Short Crack Propagation}

Preliminary results for high temperature short crack growth in U-notches indicate that the majority of the specimen life was taken up by growth and interaction of numerous short fatigue cracks, until coalescence of several cracks generated a dominant defect which propagated rapidly to failure. Following the discussion about the factors affecting crack initiation in the previous section, it is likely that the fatigue lifetimes of specimens tested under the same conditions will vary, depending upon: (i) the number of short cracks which initiate; (ii) the rate of crack initiation; (iii) the relative positions of the short cracks relative to the notch axis and to each other; (iv) the rate of crack growth and (v) the degree to which cracks interact with one another via arrest or coalescence events. Hence, a life prediction model for U-notch geometries incorporating short crack data may have to take into account microstructural factors such as primary carbide distribution, because of its effect on the number and relative positions of cracks initiated from carbides.

The remarkable straightness of surface cracks in the U-notches and their apparent transgranular path near the surface was probably a consequence of the high plastic strain field caused by the stress concentration effect of the notch. At the maximum stress of $750 \mathrm{MPa}$, the theoretical elastic stress in the notch root would be $1672.5 \mathrm{MPa}$, which is well above the yield stress and ultimate tensile strength of $\mathrm{IN} 718$ at $600^{\circ} \mathrm{C}$. In reality, plastic yielding of material around the notch occurred during testing, so that the surface cracks grew in a situation where they were mechanically short relative to the size of the notch plastic zone. It is thought that the high level of notch plasticity resulted in transgranular Stage II type crack growth at the surface, with a fairly constant fatigue crack growth rate. This implies that the local crack tip driving force was constant for short cracks growing in isolation, until it was reduced for longer crack lengths by crack shielding and interactions between the crack-tip stress fields of neighbouring cracks.

\section{Effect of Hold Time and Surface Condition}

Tests performed on U-notch specimens at $600^{\circ} \mathrm{C}$ in air show a beneficial effect of dwell times at maximum load on overall fatigue life. A 1-20-1-1 cycle increased the fatigue life by a factor of 2 compared to a 1-1-1-1 cycle. This is the same trend as that observed previously for U-notch specimens taken from an extruded bar of IN718 [18]. Crack initiation occurred within the first $20 \%$ of the overall fatigue life, so that a significant proportion of life was taken up by short crack growth and coalescence. A speculative explanation for the increased lifetime is that the dwell at maximum load retarded the growth of short cracks in the notch root, rather than affecting time to crack initiation. However, this cannot be confirmed until short crack growth rate measurements are made on U-notch specimens with a dwell at maximum load. The retardation mechanism may be stress relaxation at the crack tips in the high plastic strain field of the notch, or possibly oxide-induced crack closure.

A beneficial effect on fatigue life of polishing out broaching marks was observed, consistent with previously published results on uninterrupted tests [18]. Surface roughness is known to influence fatigue crack initiation through the creation of local stress concentrators, but the surface replica results show that even for a polished U-notch, crack initiation readily occurs. 
Alternatively, the broaching marks parallel to the U-notch axis could have influcnced crack propagation. Residual stresses effects introduced by the polishing process are considered to be unlikely, since they will be negligible compared to the plastic stress-strain field generated by the notch.

\section{Morphology of Erupted Carbides}

Volume expansion of oxidised primary carbides has already been discussed in relation to crack initiation. Volume expansion can also explain the formation of the various eruptions seen on the polished thermal exposure specimens, shown schematically in Figure 16.

Before Oxidation

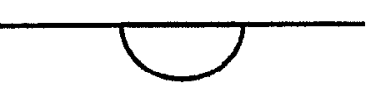

(a)

(b)
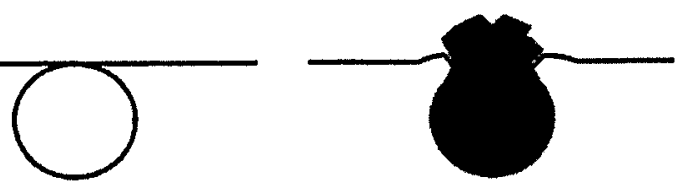

(c)
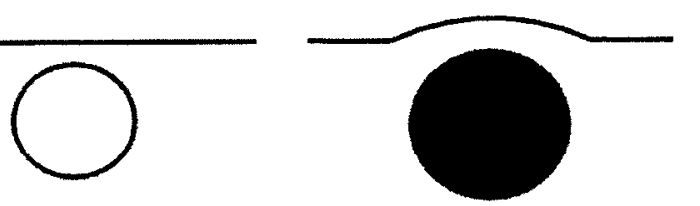

Figure 16: Schematic diagram of different primary carbide oxidation scenarios. (a) Exposed carbide on polished surface; (b) Carbide just intersecting surface; (c) Sub-surface carbide causing matrix deformation.

The layered, tower-like eruptions observed on polished surfaces are possibly the result of a lamellar oxidation process. The flat surface of a carbide exposed on the polished surface is easily oxidised. Volume expansion due to oxidation raises the oxidised material proud of the surface. The oxide/carbide interface created then provides a preferential oxygen diffusion path for further oxidation. Another layer of oxide forms and expands, forming another oxide/carbide interface. This process continues, building the observed layered eruption (Figure 16a). Alternatively, the layered appearance could be crystallographic in nature, because the primary carbides have a cubic crystal structure, while the various forms of $\mathrm{Nb}_{2} \mathrm{O}_{5}$ are reported to be orthorhombic or monoclinic [22]. For carbides only just exposed at the surface, constraint by the matrix prevents free expansion of the oxide, resulting in a more irregular surface eruption and some matrix deformation (Figure 16b). This situation is also thought to apply for surface eruptions observed on rougher, machined surfaces like a broached U-notch. The third scenario is where a sub-surface carbide oxidises, and mismatch stresses due to the volume change between carbide and oxide are sufficiently high to cause matrix deformation (Figure 16c).

\section{Conclusions}

Fatigue crack initiation and growth in U-notch specimens taken from an N718 turbine disc forging was studied at $600^{\circ} \mathrm{C}$ in air, using $1-1-1-1$ and 1-20-1-1 cycles. SEM examination and cellulose acetate replication enabled detailed study of crack initiation and subsequent crack growth. Thermal exposure experiments on unstressed specimens provided further information about the role of primary carbide oxidation in crack initiation.

SEM observations on interrupted tests in air at $600^{\circ} \mathrm{C}$ and an acetate replica study showed that crack initiation in U-notch specimens occurred early within the overall fatigue life, so that a significant proportion of life was taken up by short crack growth and coalescence. Short crack growth rates in a U-notch spccimcn tested using a 1-1-1-1 loading cycle at $600^{\circ} \mathrm{C}$ in air tended to be constant, except when crack-crack interactions resulted in arrest or coalescence. This has implications for life predictions of U-notch specimens, since the overall life will vary according to the distribution of crack initiation sites such as primary carbides, the rate at which cracks nucleate and the rate at which they grow and coalesce to form a dominant defect.

Compared to a 1 second dwell, a dwell time of 20 seconds at maximum load had a beneficial effect on the fatigue lifetimes of U-notch specimens. Polishing the U-notch to remove broaching marks also had a beneficial effect on fatigue life under the test conditions used.

Oxidation of $(\mathrm{Nb}, \mathrm{Ti}) \mathrm{C}$ primary carbides in $\mathrm{IN718}$ readily occurred at temperatures of $550-600^{\circ} \mathrm{C}$. The volume expansion due to oxidation was sufficient to cause substantial plastic deformation of the surrounding matrix. Surface eruptions of oxidiscd material were observed in thermal exposure and fatigue specimens.

For crack initiation in U-notch specimens of IN718, it is proposed that the misfit strains due to primary carbide oxidation were superimposed on the plastic strain field in the U-notch due to external loading. This would create local strains high enough to cause rupture of the matrix, hence initiating a fatigue crack. Examination of crack initiation sites in U-notch fatigue specimens confirmed that localised matrix deformation due to sub-surface carbide oxidation was a significant mechanism of fatigue crack initiation in the notch root.

\section{Acknowledgements}

This work was funded by the United Kingdom Engineering and Physical Sciences Research Council and ABB-ALSTOM Power Generation UK Limited. The authors wish to thank Dr. S. J. Moss and $M$. Hughes of ABB-ALSTOM Power Generation for valuable technical discussions and provision of the IN718 material. We also wish to acknowledge the use of the EPSRC's Chemical Database Service at Daresbury. 
References

[1] L. A. James "Fatigue Crack Propagation in Alloy 718: A Review" Proc. Conf. Superalloy 718 - Metallurgy \& Applications, Ed. E. A. Loria, TMS, Warrendale PA, USA (1989), 499-515

[2] M. Clavel \& A. Pineau "Frequency and Wave-Form Effects on the Fatigue Crack Growth Behavior of Alloy 718 at $298 \mathrm{~K}$ and 823K" Metall. Trans. A. 9 (1978), 471-480

[3] H. Ghonem, T. Nicholas \& A. Pineau "Elevated Temperature Fatigue Crack Growth in Alloy 718-Part I: Effects of Mechanical Variables" Fatigue Fract. Eng. Mater. Struct. 16 (1993), 565-576

[4] J. P. Pedron \& A. Pineau "The Effect of Microstructure and Environment on the Crack Growth Behaviour of Inconel 718 Alloy at $650^{\circ} \mathrm{C}$ Under Fatigue, Creep and Combined Loading" Mater. Sci. \& Eng. 56 (1982), 143-156

[5] L. A. James "The Effect of Grain Size upon the Fatigue-Crack Propagation Behavior of Alloy 718 under Hold-Time Cycling at Elevated T'emperature" Eng. Fract. Mechanics 25 (1986), 305-314

[6] S. P. Lynch et al. "Fatigue Crack Growth in Nickcl-Bascd Superalloys at $500-700^{\circ} \mathrm{C}$. II: Direct-Aged Alloy $718^{\prime \prime}$ Fatigue Fract. Eng. Mater. Struct. 17 (1994), 313-325

[7] S. Floreen \& R. H. Kane "An Investigation of the CreepFatigue-Environment Interaction in a Ni-Base Superalloy" Fatigue Eng. Mater. Struct. 2 (1980), 401-412

[8] H. H. Smith \& D. J. Michel "Effect of Environment on Fatigue Crack Propagation Behavior of Alloy 718 at Elevated Temperatures" Metall. Trans. A 17 (1986), 370-374

[9] H. Ghonem, T. Nicholas \& A. Pineuu "Elevated Temperature Fatigue Crack Growth in Alloy 718 - Part II: Effects of Environmental and Material Variables" Fatigue Fract. Eng. Mater. Struct. 16 (1993), 577-590

[10] K. J. Miller "The Short Crack Problem" Fat. Eng. Mater. Struct. 5 (1982), 223-232

[11] J. Lankford J. \& S. J. Hudak (Jr.) "Relevance of the Small Crack Problem to Lifetime Prediction in Gas Turbines" Int. J. Fatigue 9 (1987), 87-93

[12] J. Reuchet \& L. Remy "High Temperature Low Cycle Fatigue of MAR-M 509 Superalloy I: The Influence of Temperature on the Low Cycle Fatigue Bchaviour from 20 to $1100^{\circ} \mathrm{C}$ " Mater. Sci. \& Eng. 58 (1983), 19-32

[13] J.Reuchet \& L. Remy "High Temperature Low Cycle Fatigue of MAR-M 509 Superalloy II: The Influence of Oxidation at High Temperatures" Mater. Sci. \& Eng. 58 (1983), 33-42

[14] M. Reger \& L. Remy "High temperature Low Cycle Fatigue of IN 100 Superalloy I: Influence of Temperature on the Low Cycle Fatigue Behaviour" Mater. Sci. \& Eng. A 101 (1988), 4754
[15] M. Reger \& L. Remy "High Temperature Low Cycle Fatigue of IN 100 Superalloy II: Influence of Frequency and Environment at High Temperatures" Mater. Sci. \& Eng. A 101 (1988), 55-63

[16] G. Sjoberg, N-G. Ingesten \& R. G. Carlson "Grain Boundary $\delta$ Phase Morphologies, Carbides and Notch Rupture Sensitivity of Cast Alloy 718" Proc. 2nd Int. Symp. Superalloy 718,625 \& Various Derivatives Ed. E. A. Loria, TMS, Warrendale PA, USA (1991), 603-620

[17] M. Gao, D. J. Dwyer \& R. P. Wei "Niobium Enrichment and Environmental Enhancement of Creep Crack Growth in Nickel-Base Superalloys" Scr. Metall. \& Mater. 32 (1995), 1169 1174

[18] P.A.S. Reed et al. "Creep-Fatigue Initiation and Early Crack Growth in Inconel 718" Proc. 8th Int. Conf. Progress in Mechanical Behaviour of Materials (ICM8), Eds. F. Ellyin \& J. W. Provan, Fleming Printing Ltd. Victoria, BC, Canada, vol. 1 (1999), 418-423

[19] T. Connolley, P. A. S. Reed \& M. J. Starink "A Study of the Role of $(\mathrm{Nb}, \mathrm{Ti}) \mathrm{C}$ Carbides in Fatigue Crack Initiation in Inconel 718 at $20^{\circ} \mathrm{C}$ and $600^{\circ} \mathrm{C}$ " (To be published in Proc. $5^{\text {th }}$ International Charles Parsons Turbine Conference, Cambridge UK, 3rd - 7th July 2000)

[20] M. R. Bache, W. J. Evans \& M. C. Hardy "The Effects of Environment and Loading Waveform on Fatigue Crack Growth in Inconel 718 " Supplement to Int. J. Fatigue 2I (1999), S69-S77

[21] S. Shimada \& M. Inagaki "A Kinetic Study on Oxidation of Niobium Carbide" Solid State Ionics 63-65 (1993), 312-317

[22] H. Schäfer, R. Gruehn \& F. Schulte "The Modifications of Niobium Pentoxide" Angew. Chem. Internat. Edit. 5 (1966), 4052

[23] D. A. Fletcher, R. F. McMeeking \& D. Parkin "The United Kingdom Chemical Database Service" J. Chem. Inf. Comput. Sci. 36 (1996), 746-749

[24] J. K. Lee et al. "Plastic Relaxation of the Transformation Strain Energy of a Misfitting Spherical Precipitate: Ideal Plastic Behavior" Metall. Trans. A 11 (1980), 1837-1847

[25] M.J. Starink, P. Van Mourik \& B. M. Korevaar "Misfit Accommodation in a Quenched and Aged Al-Cu Alloy with Silicon Particles" Metall. Trans. A 24 (1993), 1723-1731 